Review

\title{
CXCR4/CXCLI 2 Axis in Non Small Cell Lung Cancer (NSCLC) Pathologic Roles and Therapeutic Potential
}

\author{
Ori Wald ${ }^{1,2,3}$, Oz M. Shapira ${ }^{1}$ and Uzi Izhar ${ }^{1}$ \\ 1. Department of Cardiothoracic Surgery, Hadassah University Hospital, Jerusalem, Israel; \\ 2. Goldyne Savad Institute of Gene Therapy, Hadassah University Hospital, Jerusalem, Israel; \\ 3. Laboratory for Surgical Research, Hadassah University Hospital, Jerusalem, Israel.
}

\begin{abstract}
$\square$ Corresponding author: Ori Wald M.D, Ph.D. Department of Cardiothoracic Surgery, Hadassah University Hospital, P.O Box 12000 , Jerusalem, Israel. FAX: 972-2- 5345125, Phone: 972-50-8946297, e-mail: ori.wald@mail.huji.ac.il.

(C) Ivyspring International Publisher. This is an open-access article distributed under the terms of the Creative Commons License (http://creativecommons.org/ licenses/by-nc-nd/3.0/). Reproduction is permitted for personal, noncommercial use, provided that the article is in whole, unmodified, and properly cited.
\end{abstract}

Received: 2012.07.24; Accepted: 2012.10.03; Published: 2013.0I.13

\begin{abstract}
Lung cancer is the second most common malignancy and the leading cause of cancer-related death in the western world. Moreover, despite advances in surgery, chemotherapy and radiotherapy, the death rate from lung cancer remains high and the reported overall five-year survival rate is only 15\%. Thus, novel treatments for this devastating disease are urgently needed. Chemokines, a family of 48 chemotactic cytokines interacts with their 7 transmembrane G-protein-coupled receptors, to guide immune cell trafficking in the body under both physiologic and pathologic conditions. Tumor cells, which express a relatively restricted repertoire of chemokine and chemokine receptors, utilize and manipulate the chemokine system in a manner that benefits both local tumor growth and distant dissemination. Among the 19 chemokine receptors, CXCR4 is the receptor most widely expressed by malignant tumors and whose role in tumor biology is most thoroughly studied. The chemokine CXCLI 2, which is the sole ligand of CXCR4, is highly expressed in primary lung cancer as well as in the bone marrow, liver, adrenal glands and brain, which are all sites for lung cancer metastasis. This review focuses on the pathologic role of the CXCR4/CXCLI 2 axis in NSCLC and on the potential therapeutic implication of targeting this axis for the treatment of NSCLC.
\end{abstract}

Key words: NSCLC, Lung, Human, Chemokines.

\section{Introduction - Lung Cancer}

Lung cancer is the second most common malignancy and continues to be the leading cause of cancer-related death in both men and women in the United States and throughout the world (1). Lung cancer causes more deaths than the next four common cancers combined - colon, breast, pancreas and prostate $(1,2)$. Epidemiologic evidence and the complementary biological understanding of respiratory carcinogenesis support the conclusion that cigarette smoking causes lung cancer (3-6). Other occupational and environmental causes are being increasingly associated with lung cancer include exposure to radon, asbestos, outdoor air pollution and many other chemicals (3-6). It has been estimated that over 220,000 new cases of lung cancer would be diagnosed in the United States in 2012 (7). Despite advances over the last decade in diagnostic, staging and surgical techniques as well as new chemotherapy and radiotherapy protocols, the death rate from lung cancer remains high (8). Lung cancer-related mortality is anticipated to peak above 160,000 cases/year and the reported overall five-year survival rate is only $15 \%$ (7). The anticipated implementation of nation-wide lung cancer screening programs will increase the proportion of patients diagnosed in early disease stages permitting such patients to undergo surgical resection, which is considered the best therapeutic 
approach (9). Nonetheless, the five years survival rates of these surgically treated patient, with or without the addition of adjuvant chemotherapy or radiotherapy is approximately $50 \%(10,11)$. Following primary tumor development the disease tends to progress along three distinct, yet often concomitantly occurring pathways: 1 . Local invasion of the tumor to adjacent structures in the mediastinum and the chest wall. 2. Lymphatic spread to regional lymph nodes 3. Hematogenous spreading of distant metastases, most commonly to the liver, adrenal glands, bone marrow and the brain (10-13). Each of these three manifestations of disease is only partially addressed by current medical and surgical treatments protocols, and novel therapeutic approaches that tackle each of these clinical manifestations are urgently needed (10-13).

Similar to many other solid epithelial malignancies, staging of lung cancer is based on the TNM classification system (14). The anatomical extent of disease is based on the assessment of three components: $\mathrm{T}$ - the extent of the primary tumor, $\mathrm{N}$ - the absence or presence of regional lymph nodes metastases, $\mathrm{M}$ - the absence or presence of distant metastases. This clinical staging is essential to select and evaluate therapy, and such evidence arises from physical examination, imaging, endoscopy, biopsy and surgical exploration (15). Pathologically lung cancer is classified into non-small cell lung cancer (NSCLC) accounting for $80 \%$ of cases, and small cell lung cancer (SCLC) accounting for the remaining $20 \%(16,17)$. NSCLC originates from respiratory epithelial cells and adenocarcinoma is the most common histologic subtype in most countries, accounting for almost half of all lung cancers (18). The clinical, radiologic, molecular and pathologic spectrum is widely divergent within lung adenocarcinoma, and recently a new classification has been revised (18). The second most common type of lung cancer is squamous cell carcinoma and the least common type is large cell carcinoma (16-18). SCLC stem from cells with neuroendocrine differentiation that are located at distinct anatomic sites along the bronchial tree (19). The majority of data reviewed in this manuscript relates to NSCLC adenocarcinomas.

\section{CXCR4 Expression, Regulation and Func- tion in Solid Malignancies}

Chemokines, a family of 48 chemotactic cytokines interact with their 7 transmembrane G-protein-coupled receptors to guide immune cell trafficking in the body under both physiologic and pathologic conditions $(20,21)$. Tumor cells, which express a relatively restricted repertoire of chemokine and chemokine receptors, utilize and manipulate the chemokine system in a manner that benefits both local tumor growth and distant dissemination $(20,22,23)$. In the tumor microenvironment autocrine and paracrine chamokine/chemokine receptor loops interact to promote tumor cell survival and growth, and also to enhance tumor neo-angiogenesis $(20,22,23)$. At distant sites, it is the tissue-produced chemokine which guide/attracts the metastasis of chemokine receptor expressing tumor cells (20).

Among the 19 chemokine receptors, CXCR4 is the receptor most widely expressed by malignant tumors and whose role in tumor biology is most thoroughly studied (20). The chemokine CXCL12 is the sole ligand of CXCR4 and the majority of research that focus on the role of CXCR4 in cancer relates to this chemokine/chemokine receptor pair $(24,25)$. Nevertheless, in 2006 another receptor for CXCL12 was identified and named CXCR7 (26). CXCR7 is expressed during embriogenesis, angiogenesis and in various malignant tissues including NSCLC. CXCR7 is thought to act in part as a scavenger of CXCL12 however additional functions for this receptor have also been reported (26-28). In distinct form CXCR4, CXCR7 binds not only CXCL12 but also the chemokine CXCL11 $(26,27)$. Moreover, the signaling cascades that are generated upon binding of CXCL12 to CXCR4 or CXCR7 vary at least partly, depending on which of the receptors is engaged $(26,27)$. This review focuses mainly on data collected regarding the expression and function of CXCR4 in NSCLC, nevertheless it is important to keep in mind that whenever CXCL12 is mentioned the effects related to its expression may be attributed in part to CXCR7 expression and function.

Relative to normal cells in the tumor's tissue of origin, malignant cells often over express CXCR4, this phenotype can be induced by multiple oncogenic alternations and appears to promote tumor cell survival, proliferation, invasion and metastasis $(20,29-35)$. For example, the RET/PTC rearrangement was shown to enhance CXCR4 expression in papillary thyroid carcinomas and this was associated with increased responsiveness of the malignant cells to CXCL12, leading to entry into S-phase and to enhanced survival of the tumor cells (36). Furthermore in the same study the researchers found that invasion through extracellular matrix was also supported by CXCL12 stimulation and inhibited by CXCR4 blocking antibodies (36). Along similar lines, Yan M. Li et al found that aberrant activation of the human epithelial growth factor receptor HER-2 in breast cancer cells results in PI-3K/Akt/mTOR pathway dependant up-regulation of CXCR4, that in turn enhances tumor cell invasion in vitro and lung metastasis in vivo (37). 
In addition to oncogenic alternations, the tumor microenvironment may also greatly affect the tumor's CXCR4 expression levels (38). For example, low tissue oxygen levels result in Hypoxia Inducible Factor 1 (HIF-1) expression that in turn up-regulates CXCR4 leading to enhanced NSCLC tumor cell invasion and metastasis (38). Likewise, in glioblastoma tumors, both HIF-1 and vascular endothelial growth factor (VEGF) were found to enhance CXCR4-dependant angiogenesis in the tumors (39). Thus it appears that, regardless of the reasons behind CXCR4 expression, the over-expression of this receptor renders tumor cells responsive to CXCL12-induced signaling, which in turn promotes their survival, proliferation, angiogenesis and metastasis $(40,41)$.

\section{Pathologic Role For CXCR4/CXCL12 in Non-Small Cell Lung Cancer}

Two line of evidence provide insight into the role of CXCR4/CXCL12 in NSCLC malignant propagation. The first comes from retrospective studies of human metastatic cancers, in which high CXCR4/CXCL12 expression levels are associated with a more advanced diseases stage and with worse prognosis $(12,25,42-44)$. The second evidence comes from experimental in vitro and in vivo studies, which indicate that CXCR4/CXCL12 interactions in the tumor microenvironment may foster local tumor growth and that high CXCR4 expressing tumor cells, have a greater invasive and metastatic potential (12, $25,42-44)$.

Multiple retrospective studies of human NSCLC implemented immunohistochemical staining to demonstrate that all major subtypes of NSCLC tumors express CXCR4 and more specifically to show that CXCR4 expression is detected in either the cytomembranous compartment or the nuclear compartment or both compartments of the malignant cells (42-44). When examining the correlation of such CXCR4 staining with patient-specific clinical parameters of disease, $\mathrm{Su}$ and colleagues found that tumors with high cytomembranous expression of CXCR4 were more prone to locally invade neighboring anatomical structures and to form distant metastasis than were low CXCR4-expressing tumors (43). Similarly, Chen et al have found that high-level of cytomembranous CXCR4 expression correlated with brain-specific metastasis in single station M1 NSCLC patients (45). Some insight into the processes that may promote this highly metastatic phenotype of CXCR4 expressing tumor cells comes from the recent work of Franco et al. In this report the authors found that high cytomembranous expression of CXCR4 in NSCLC tumor cells was associated with a significantly in- creased in density of micro-vascular structures in the tumors and that this was associated with increased micro-vessel invasion by tumor cells (46). Further support for involvement of CXCR4 in NSCLC spread and disease outcome comes from the two additional works. First, Oonakahara and associates found that pleural mesothelial cell produced CXCL12 and that high level of CXCL12 in the pleural fluid were associated with seeding of the pleural space with CXCR4 expressing tumor cells (47). Second, a work by Otsuka et al has recently shown that CXCR4 is expressed in the cytomembranous compartment of majority of NSCLC tumors, and that its over-expression is associated with significantly poorer survival in stage IV NSCLC patients. Moreover, this poor outcome was disproportionately represented in the female population thus suggesting a gender-dependent difference in clinical outcome based on CXCR4 over-expression (48). Somewhat contradictory to these observations, Spano and associates have reported that strong CXCR4-positive nuclear staining was associated with improved outcomes in early stage NSCLC (42). In a larger study, Wagner and colleagues have confirmed the above-mentioned findings and concluded that cytomembranous expression of the CXCR4 in lung adenocarcinoma is an independent risk factor for decreased disease-free survival, whereas nuclear expression of CXCR4 confers a survival benefit (44). The prognostic usefulness of determining CXCL12 expression levels in NSCLC has also been tested (44). For instance, we found that more than $80 \%$ of NSCLC tumors expressed CXCL12 in the cytomembranous compartment and that NSCLC recurrence rates were higher $(7 / 21)$ among patients with intense CXCL12 staining than among those who had weak staining (0/8) (49). Using tumor tissue arrays we further found a correlation between high CXCL12 expression levels and an advanced pathologic stage of disease (50). Other reports have corroborated these findings, also nicely demonstrating a linkage between high tumoral CXCL12 expression levels and both a higher T score and an increased tendency to form lymph node metastasis (44). Taken together, although yet preliminary and requiring further validation, the above-mentioned studies certainly advocate in favor of a pro-malignant role for the CXCL12/CXCR4 axis in NSCLC disease progression.

An additional method to examine the potential correlation between CXCR4/CXCL12 expression and cancer patient outcomes is by performing genetic polymorphism studies that correlate distinct genetic alternations to patient-specific clinical and pathologic parameters (51). In this regard, two distinct genetics alternations in the CXCR4/CXCL12 axis have been 
characterized in the past. The first is the single nucleotide polymorphisms (SNP) in position 801 of the CXCL12 gene, (guanine to adenine $(G \rightarrow A)$, un-translated region at position 801) and the second is the SNP at codon 138 of the CXCR4 gene (the silent mutation cytosine to thymine $(\mathrm{C} \rightarrow \mathrm{T})$, at codon 138$)$ $(52,53)$. Looking at these SNPs, Hirata et al have found that prostate cancer patients that carry the CXCL12 AA trait tend to express higher levels of CXCL12 and also to up-regulate CXCR4 expression in their tumors (51). Furthermore, they found that carriers of this trait had a worse prognosis relative to GA and GG traits (51). The effects of the CXCR4 TT trait on CXCR4 expression levels are not well defined, nevertheless, the CXCR4 TT trait has been associated with more advanced disease stages in several malignancies, among them is head and neck cancer (53). Recent research by Lee and colleagues followed the same approach in order to examine the correlation of these two SNP mutations and the outcomes of NSCLC patients (52). The researchers found that individuals with the CXCL12 AA and CXCR4 TT genotypes had higher odds ratios (an OR of 1.95, 95\% CI 1.08-3.50, p $=0.018$ and OR of $4.71,95 \%$ CI 1.99-11.2, $p<0.0001$ respectively) for lung cancer development and that NSCLC patients with the CXCL12 AA and CXCR4 TT genotypes more frequently had an advanced disease stage and a worse prognosis (52). This study thus further provides evidence for the pro-malignant role for CXCL12/CXCR4 in NSCLC.

The above-mentioned studies point toward two distinct mechanisms by which CXCL12/CXCR4 interactions may promote NSCLC progression. First the association of high CXCR4 expression levels in the primary tumor with distant metastasis suggests that this receptor is involved in NSCLC disease spread. Second, the high expression of CXCL12 in the tumor microenvironment suggests that CXCR4/CXCL12 interaction may act locally in autocrine and paracrine manners to enhance primary tumor growth and to alter its inflammatory milieu. Experimental evidence in support of the role of CXCR4 in NSCLC metastasis comes from the work of Phillips and colleagues who demonstrated that administration of anti-CXCL12 neutralizing antibodies to immunodeficient mice harboring human NSCLC tumors abrogated organ specific metastasis $(54,55)$. Recent research also suggests that CXCR4/CXCL12 interactions can advance NSCLC local tumor growth (50). For examples, we have shown in a series of studies that CXCL12 stimulation enhances the colony forming capacity of NSCLC cells and that drugs such as AMD3100 and BKT140, which specifically block the CXCL12/CXCR4 axis, inhibit NSCLC growth in vitro and in vivo (50,
56-58). Finally, the inflammatory milieu of NSCLC tumors may also be affected by the CXCL12/CXCR4 axis $(49,59)$. In this regard we have shown that CXCL12 protein levels in NSCLC tumors are significantly higher relative to CXCL12 levels in the serum and that stimulation of NSCLC cells with CXCL12 induces the production of additional pro-inflammatory (CCL20) and pro-angiogenic (CXCL1 - IL-8) chemokines $(49,50)$. Furthermore, we found an increased inflammatory load in NSCLC tumors that expressed high levels of CXCL12 relative to tumors that expressed low levels of CXCL12 (49). Thus, CXCL12 may participate in shaping the tumor microenvironment by affecting the recruitment/retention of immune and bone marrow derived cell in the tumor. Also noteworthy are the works that report the expression of CXCR4 in the nucleus $(43,44)$. The role of CXCR4 in this sub-cellular compartment is yet unknown and if indeed validated, it may lay direction for intriguing future research.

\section{Role for CXCR4 in NSCLC Tumor initi- ating cells (cancer stem cells) biology}

Cancer initiating cells (CIC), also referred to as cancer stem cells, are functionally defined by their high self-renew capacities and by their potential to recapitulate tumors in ectopic setting (60-63). In addition, CIC are considered to possess drug-resistance properties indicating an important role for these cells in disease relapse following treatment (60-63). In recent years, several groups have reported the identification of NSCLC cells with CIC-like properties, and argued that patients with tumors harboring increased number of these CIC have a worse prognosis (64). Various membranous expressed proteins (CD133, CD166, CD24, CD44 and CD117), intracellular enzymes (saldehyde dehydrogenase 1 (ALDH 1) and glycine decarboxylase (GLDC)) and additional proteins (OCT-4 SOX2 and ABCG2) were used to isolate and characterize the NSCLC CIC population, therefore suggesting that great heterogeneity may actually exist in this unique subpopulation of tumor cells (12, 61-66). Interestingly, recent reports argue that CXCR4 is expressed by NSCLC CIC and is functionally important for maintenance of their unique characteristics $(65,67)$. For example, Bertolini et al has found that NSCLC cells with high self-renewal capacity and with increased chemotherapeutic resistant expressed high levels of CXCR4 relative to NSCLC that lack these characteristics (67). Similarly, Jung et al have shown that pharmacological inhibition and/or siRNA targeting of CXCR4 and of the downstream action of STAT3 significantly suppressed the self renewal capacity of various NSCLC cell lines and concluded that 
CXCR4 positive NSCLC cells are strong candidates for tumorigenic stem-like cancer cells that maintain stemness through a CXCR4-mediated STAT3 pathway (65). In addition, Damelin and colleagues suggested that CXCR4 might act downstream to the transcription factor 5T4 in epithelialto-mesenchymal transition (EMT) and in migration of NSCLC CIC (68). Taken together, these studies provide evidence in support of the existence of subpopulations of NSCLC cells with stem-like properties and also mark CXCR4 as an important player in their unique biology. Considering the resistance of NSCLC CIC to conventional chemotherapeutic drugs it is reasonable to speculate that in the clinical setting such CICs may be responsible for treatment failure and disease recurrence following therapy (69).

\section{Therapeutic Potential of CXCR4 Antago- nists Against Non Small Cell Lung Can- cer}

Multiple solid malignant tumors such as breast, prostate, colorectal and pancreatic carcinomas, in addition to gliomas, neuroblastomas, osteosarcoma, and NSCLC express CXCR4 (70). As reviewed above, CXCR4 plays a complex role in the evolution and progression of these malignancies, acting in multiple ways to increase both local tumor growth and metastatic spread $(22,23,71)$. CXCR4 has additionally been found to be involved in regulating tumor vascularization and in facilitating the interaction between tumor cells and stromal cells in a manner that favors activation of adhesion-mediated drug and radiation-resistance pathways $(25,72,73)$. Finally CXCR4 also appears to play a critical role in biology of cancer stem cells (65). Thus, it is unsurprising that the CXCR4/CXCL12 axis is considered as an exciting target for the development of novel anti-cancer chemokine-based therapeutics $(25,70,74)$. Indeed, considering the accumulating data regarding the role of CXCR4 in NSCLC biology and the urgent need for novel therapeutics for this devastating disease it is tempting to speculate that CXCR4 antagonists will join in the near future the current armamentarium of drugs that are utilized against NSCLC.

Currently over 15 new drugs that target the CXCR4/CXCL12 axis are being developed with one drug, AMD3100 (also known as Plerixafor and Mozobil), already gaining FDA approval (70, 75-77). The indication for AMD3100 administration however is mobilization of hematopoietic stem cells for bone marrow transplantation rather than cancer treatment (76). Nevertheless AMD3100 and BKT140, an additional CXCR4 antagonist, have been reported to act in conjunction with conventional anticancer therapies against human NSCLC $(50,65)$. AMD3100 has been reported to render chemotherapeutic resistant NSCLC CIC to chemotherapy and was further shown to prevent these cells from maintaining their stem like properties (65). Similarly, BKT140 was shown to act in an additive manner with cisplatin, paclitaxel and radiation pretreatment to prevent NSCLC tumor cell proliferation (58). Although these findings are very encouraging, some key issues deserve proper consideration prior to designing clinical trials that utilize CXCR4 inhibitors for treatment of cancer (70). One intriguing issue to define is whether CXCR4 inhibitors should be administered in order to prevent disease spread or rather in order to enhance the effects of concomitantly administered drugs/radiation against preexisting tumors. The answer to this question will probably further guide the duration of drug administration: chronic administration versus pulse therapy in combination with chemo/radiotherapy. Another important topic to consider is the potential harmful effects of prolonged anti-CXCR4 therapy. While short administration of anti-CXCR4 drugs is considered to have a relatively tolerable profile of side effects, the prolonged effects of such drugs are less clear (70, 75-77). This issue is of great concern since CXCR4/CXCL12 interactions are involved in a number of essential homeostatic processes in the body such as regulating the recirculation of hematopoietic stem cells (78-80). More specifically, it is questionable whether prolonged mobilization of hematopoietic stem cells is tolerable and whether the effects of mobilized bone marrow cells on the tumor will be pro or anti metastatic. An intriguing possibility to overcome some of these concerns was recently introduced by the group of Liang et al who reported about the development of a novel small molecule, MSX-122, that is a partial CXCR4 antagonist without stem cell mobilizing properties (81). The researchers speculate that drugs such as MSX-122 may be safely administered for long-term blockade of metastasis avoiding the side effects of stem cell mobilization (81). Nonetheless, it seems that, when taking into account the characteristics of the CXCR4 antagonists that have already been approved for use in clinical trials (see ref no 62) and when considering the potential roles of CXCR4 in NSCLC, it might be more logical to first design clinical studies that will examine the short term effects of CXCR4 antagonist administration. More specifically, such studies should measure the potential additive effects of combining CXCR4 antagonists with current chemotherapeutic / radiation protocols in attempt to increase and prolong their effects. As mentioned, the alternative approach of attempting to prevent metas- 
tasis formation may require long-term administration of CXCR4 antagonist, which could possibly result in significant side effect. In addition studies that focus on metastasis inhibition might be more complex to design and will necessitate a longer follow up period prior to concluding their outcomes. Thus, the short-term approach seems to offer an ideal next step in the urgent need to develop novel therapeutics to NSCLC.

\section{Potential Roles For CXCR4/CXCL12 in NSCLC}

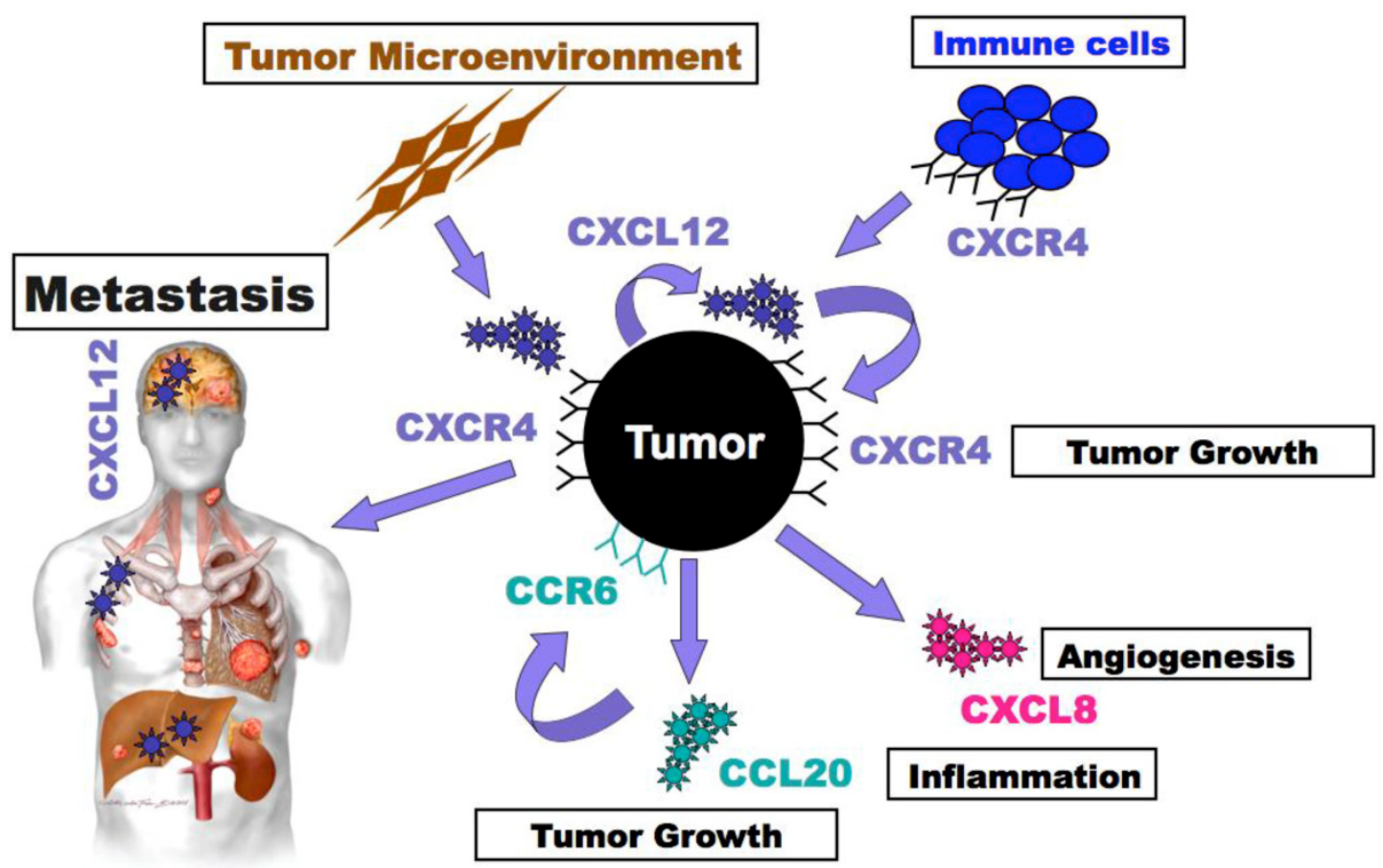

Figure I. Potential roles for CXCR4/CXCLI 2 in NSCLC._NSCLC tumor cells express CXCR4 and produce CXCLI2. Tumor expressed CXCR4 guides metastatic spread to sights such as the brain, bone marrow and liver that express high levels of CXCLI2. In addition, CXCR4/CXCLI 2 interactions act locally in autocrine and paracrine manners to enhance primary tumor growth and to alter its inflammatory milieu. Tumor and tumor microenvironment secreted CXCLI 2 enhance tumor cell survival and growth and may also guide trafficking of immune and bone marrow derived cells into the tumor microenvironment. Furthermore, alternations in the tumor microenvironment result from the stimulation of tumor cells with CXCLI 2 that in turn enhance the production of additional chemokines such as the pro-inflammatory and pro-proliferative chemokine CCL20) pro-angiogenic and pro-proliferative chemokine (CXCLI - IL-8).

\section{Concluding Remarks}

In the last decade much has been learned about the role of CXCR4/CXCL12 axis in solid malignancies in general and in NSCLC in particular $(12,20,21)$. Nowadays, this knowledge is on the edge of being translated into clinical trials that will examine the potential of CXCR4/CXCL12 antagonist to fight cancer (70). The urgent need for new therapeutic approaches for NSCLC patients make this disease an attractive target for such evolving trials.

\section{Recommended Readings}

1. For a recent overview of CXCR4 signaling, development of novel CXCR4-based therapeutics, and current clinical trials, the readers are referred to reference number 70 .

2. For an overview about the identification of CXCR4 expression in tumor cells as a diagnostic and therapeutic tool, the readers are referred to the manuscript by Jacobson and Weiss et al in this issue of Theranostics Journal.

\section{Acknowledgement}

The Israeli Science Foundation Morasha research grant program supported this work.

\section{Competing Interests}

The authors have declared that no competing interest exists. 


\section{References}

1. Jemal A, Siegel R, Xu J, Ward E. Cancer statistics, 2010. CA Cancer J Clin 2010;60(5):277-300.

2. Jemal A, Siegel R, Ward E, Murray T, Xu J, Thun MJ. Cancer statistics, 2007. CA Cancer J Clin 2007;57(1):43-66.

3. Spiro SG, Silvestri GA. One hundred years of lung cancer. Am J Respir Crit Care Med 2005 Sep 1;172(5):523-9.

4. Pao W, Girard N. New driver mutations in non-small-cell lung cancer. Lancet Oncol 2011 Feb;12(2):175-80.

5. Pao W, Hutchinson KE. Chipping away at the lung cancer genome. Nat Med 2012 Mar;18(3):349-51.

6. Alberg AJ, Ford JG, Samet JM. Epidemiology of lung cancer: ACCP evidence-based clinical practice guidelines (2nd edition). Chest 2007 Sep;132(3 Suppl):29S-55S.

7. Siegel R, Naishadham D, Jemal A. Cancer statistics, 2012. CA Cancer J Clin 2012;62(1):10-29.

8. Siegel R, Desantis C, Virgo K, Stein K, Mariotto A, Smith T, et al. Cancer treatment and survivorship statistics, 2012. CA Cancer J Clin 2012 Jul;62(4):220-41.

9. Aberle DR, Adams AM, Berg CD, Black WC, Clapp JD, Fagerstrom RM, et al. Reduced lung-cancer mortality with low-dose computed tomographic screening. N Engl J Med 2011 Aug 4;365(5):395-409.

10. Murthy SC, Reznik SI, Ogwudu UC, Farver CF, Arrossi A, Batizy LH, et al. Winning the battle, losing the war: the noncurative "curative" resection for stage I adenocarcinoma of the lung. Ann Thorac Surg 2010 Oct;90(4):1067-74.

11. Hubbard MO, Fu P, Margevicius S, Dowlati A, Linden PA. Five-year survival does not equal cure in non-small cell lung cancer: A Surveillance, Epidemiology, and End Results-based analysis of variables affecting 10- to 18-year survival. J Thorac Cardiovasc Surg. 2012.

12. Saintigny P, Burger JA. Recent advances in non-small cell lung cancer biology and clinical management. Discov Med 2012 Apr;13(71):287-97.

13. Triano LR, Deshpande H, Gettinger SN. Management of patients with advanced non-small cell lung cancer: current and emerging options. Drugs 2010;70(2):167-79.

14. Kameyama K, Takahashi M, Ohata K, Igai H, Yamashina A, Matsuoka T, et al. Evaluation of the new TNM staging system proposed by the International Association for the Study of Lung Cancer at a single institution. J Thorac Cardiovasc Surg 2009 May;137(5):1180-4.

15. Detterbeck FC, Boffa DJ, Tanoue LT. The new lung cancer staging system. Chest 2009 Jul;136(1):260-71.

16. Goldstraw P, Crowley J, Chansky K, Giroux DJ, Groome PA, Rami-Porta $\mathrm{R}$, et al. The IASLC Lung Cancer Staging Project: proposals for the revision of the TNM stage groupings in the forthcoming (seventh) edition of the TNM Classification of malignant tumours. J Thorac Oncol 2007 Aug;2(8):706-14.

17. Groome PA, Bolejack V, Crowley JJ, Kennedy C, Krasnik M, Sobin LH, et al. The IASLC Lung Cancer Staging Project: validation of the proposals for revision of the $\mathrm{T}, \mathrm{N}$, and $\mathrm{M}$ descriptors and consequent stage groupings in the forthcoming (seventh) edition of the TNM classification of malignant tumours. J Thorac Oncol 2007 Aug;2(8):694-705.

18. Travis WD, Brambilla E, Noguchi M, Nicholson AG, Geisinger KR, Yatabe $Y$, et al. International association for the study of lung cancer/american thoracic society/european respiratory society international multidisciplinary classification of lung adenocarcinoma. J Thorac Oncol 2011 Feb;6(2):244-85.

19. Sutherland KD, Berns A. Cell of origin of lung cancer. Mol Oncol 2010 Oct; $4(5): 397-403$

20. Zlotnik A, Burkhardt AM, Homey B. Homeostatic chemokine receptors and organ-specific metastasis. Nat Rev Immunol 2011 Sep;11(9):597-606.

21. Zlotnik A, Yoshie O. Chemokines: a new classification system and their role in immunity. Immunity 2000 Feb;12(2):121-7.

22. Mantovani A. Chemokines in neoplastic progression. Semin Cancer Biol 2004 Jun;14(3):147-8.

23. Mantovani A, Allavena P, Sozzani S, Vecchi A, Locati M, Sica A. Chemokines in the recruitment and shaping of the leukocyte infiltrate of tumors. Semin Cancer Biol 2004 Jun;14(3):155-60.

24. Bleul CC, Farzan M, Choe H, Parolin C, Clark-Lewis I, Sodroski J, et al. The lymphocyte chemoattractant SDF-1 is a ligand for LESTR/fusin and blocks HIV-1 entry. Nature 1996 Aug 29;382(6594):829-33.

25. Burger JA, Stewart DJ, Wald O, Peled A. Potential of CXCR4 antagonists for the treatment of metastatic lung cancer. Expert Rev Anticancer Ther 2011 Apr;11(4):621-30.

26. Burns JM, Summers BC, Wang Y, Melikian A, Berahovich R, Miao Z, et al. A novel chemokine receptor for SDF-1 and I-TAC involved in cell survival, cell adhesion, and tumor development. J Exp Med 2006 Sep 4;203(9):2201-13.

27. Zabel BA, Lewen S, Berahovich RD, Jaen JC, Schall TJ. The novel chemokine receptor CXCR7 regulates trans-endothelial migration of cancer cells. Mol Cancer 2011;10:73.

28. Boldajipour B, Mahabaleshwar H, Kardash E, Reichman-Fried M, Blaser $\mathrm{H}$, Minina S, et al. Control of chemokine-guided cell migration by ligand sequestration. Cell 2008 Feb 8;132(3):463-73.

29. Staller P, Sulitkova J, Lisztwan J, Moch H, Oakeley EJ, Krek W. Chemokine receptor CXCR4 downregulated by von Hippel-Lindau tumour suppressor pVHL. Nature 2003 Sep 18;425(6955):307-11.

30. Boudot A, Kerdivel G, Habauzit D, Eeckhoute J, Le Dily F, Flouriot G, et al. Differential estrogen-regulation of CXCL12 chemokine receptors, CXCR4 and CXCR7, contributes to the growth effect of estrogens in breast cancer cells. PLoS One 2011;6(6):e20898.

31. Jacobson O, Weiss ID, Kiesewetter DO, Farber JM, Chen X. PET of tumor CXCR4 expression with 4-18F-T140. J Nucl Med 2010 Nov;51(11):1796-804.

32. Jacobson O, Weiss ID, Szajek LP, Niu G, Ma Y, Kiesewetter DO, et al. PET imaging of CXCR4 using copper-64 labeled peptide antagonist. Theranostics 2011;1:251-62.

33. Muller A, Homey B, Soto H, Ge N, Catron D, Buchanan ME, et al. Involvement of chemokine receptors in breast cancer metastasis. Nature 2001 Mar 1;410(6824):50-6.

34. Raman D, Baugher PJ, Thu YM, Richmond A. Role of chemokines in tumor growth. Cancer Lett 2007 Oct 28;256(2):137-65.

35. Scala S, Ottaiano A, Ascierto PA, Cavalli M, Simeone E, Giuliano P, et al. Expression of CXCR4 predicts poor prognosis in patients with malignant melanoma. Clin Cancer Res 2005 Mar 1;11(5):1835-41.

36. Castellone MD, Guarino V, De Falco V, Carlomagno F, Basolo F, Faviana $\mathrm{P}$, et al. Functional expression of the CXCR4 chemokine receptor is induced by RET/PTC oncogenes and is a common event in human papillary thyroid carcinomas. Oncogene 2004 Aug 5;23(35):5958-67.

37. Li YM, Pan Y, Wei Y, Cheng X, Zhou BP, Tan M, et al. Upregulation of CXCR4 is essential for HER2-mediated tumor metastasis. Cancer Cell 2004 Nov;6(5):459-69.

38. Liu YL, Yu JM, Song XR, Wang XW, Xing LG, Gao BB. Regulation of the chemokine receptor CXCR4 and metastasis by hypoxia-inducible factor in non small cell lung cancer cell lines. Cancer Biol Ther 2006 Oct;5(10):1320-6.

39. Zagzag D, Lukyanov Y, Lan L, Ali MA, Esencay M, Mendez O, et al. Hypoxia-inducible factor 1 and VEGF upregulate CXCR4 in glioblastoma: implications for angiogenesis and glioma cell invasion. Lab Invest 2006 Dec;86(12):1221-32.

40. Darash-Yahana M, Pikarsky E, Abramovitch R, Zeira E, Pal B, Karplus R, et al. Role of high expression levels of CXCR4 in tumor growth, vascularization, and metastasis. FASEB J 2004 Aug;18(11):1240-2.

41. Scala S, Giuliano P, Ascierto PA, Ierano C, Franco R, Napolitano M, et al. Human melanoma metastases express functional CXCR4. Clin Cancer Res 2006 Apr 15;12(8):2427-33.

42. Spano JP, Andre F, Morat L, Sabatier L, Besse B, Combadiere C, et al. Chemokine receptor CXCR4 and early-stage non-small cell lung cancer: pattern of expression and correlation with outcome. Ann Oncol 2004 Apr;15(4):613-7.

43. Su L, Zhang J, Xu H, Wang Y, Chu Y, Liu R, et al. Differential expression of CXCR4 is associated with the metastatic potential of human non-small cell lung cancer cells. Clin Cancer Res 2005 Dec 1;11(23):8273-80.

44. Wagner PL, Hyjek E, Vazquez MF, Meherally D, Liu YF, Chadwick PA, et al. CXCL12 and CXCR4 in adenocarcinoma of the lung: association with metastasis and survival. J Thorac Cardiovasc Surg 2009 Mar;137(3):615-21.

45. Chen G, Wang Z, Liu XY, Liu FY. High-level CXCR4 expression correlates with brain-specific metastasis of non-small cell lung cancer. World J Surg 2011 Jan;35(1):56-61.

46. Franco R, Pirozzi G, Scala S, Cantile M, Scognamiglio G, Camerlingo R, et al. CXCL12-binding receptors expression in non-small cell lung cancer relates to tumoral microvascular density and CXCR4 positive circulating tumoral cells in lung draining venous blood. Eur J Cardiothorac Surg 2011 Feb;41(2):368-75.

47. Oonakahara K, Matsuyama W, Higashimoto I, Kawabata M, Arimura K, Osame M. Stromal-derived factor-1alpha/CXCL12-CXCR 4 axis is involved in the dissemination of NSCLC cells into pleural space. Am J Respir Cell Mol Biol 2004 May;30(5):671-7.

48. Otsuka S, Klimowicz AC, Kopciuk K, Petrillo SK, Konno M, Hao D, et al. CXCR4 overexpression is associated with poor outcome in females diagnosed with stage IV non-small cell lung cancer. J Thorac Oncol 2011 Jul;6(7):1169-78. 
49. Wald O, Izhar U, Amir G, Avniel S, Bar-Shavit $\mathrm{Y}$, Wald H, et al. CD4+CXCR4highCD69+ T cells accumulate in lung adenocarcinoma. J Immunol 2006 Nov 15;177(10):6983-90.

50. Wald O, Izhar U, Amir G, Kirshberg S, Shlomai Z, Zamir G, et al. Interaction between neoplastic cells and cancer-associated fibroblasts through the CXCL12/CXCR4 axis: role in non-small cell lung cancer tumor proliferation. J Thorac Cardiovasc Surg 2011 Jun;141(6):1503-12.

51. Hirata H, Hinoda Y, Kikuno N, Kawamoto K, Dahiya AV, Suehiro Y, et al. CXCL12 G801A polymorphism is a risk factor for sporadic prostate cancer susceptibility. Clin Cancer Res 2007 Sep 1;13(17):5056-62

52. Lee YL, Kuo WH, Lin CW, Chen W, Cheng WE, Chen SC, et al. Association of genetic polymorphisms of CXCL12/SDF1 gene and its receptor, CXCR4, to the susceptibility and prognosis of non-small cell lung cancer. Lung Cancer 2011 Aug;73(2):147-52.

53. Teng $\mathrm{YH}$, Liu TH, Tseng HC, Chung TT, Yeh CM, Li YC, et al. Contribution of genetic polymorphisms of stromal cell-derived factor-1 and its receptor, CXCR4, to the susceptibility and clinicopathologic development of oral cancer. Head Neck 2009 Oct;31(10):1282-8.

54. Phillips RJ, Burdick MD, Lutz M, Belperio JA, Keane MP, Strieter RM. The stromal derived factor-1/CXCL12-CXC chemokine receptor 4 biological axis in non-small cell lung cancer metastases. Am J Respir Crit Care Med 2003 Jun 15;167(12):1676-86.

55. Phillips RJ, Mestas J, Gharaee-Kermani M, Burdick MD, Sica A, Belperio JA, et al. Epidermal growth factor and hypoxia-induced expression of CXC chemokine receptor 4 on non-small cell lung cancer cells is regulated by the phosphatidylinositol 3-kinase/PTEN/AKT/mammalian target of rapamycin signaling pathway and activation of hypoxia inducible factor-1alpha. J Biol Chem 2005 Jun 10;280(23):22473-81.

56. Fujii N, Nakashima $H$, Tamamura $H$. The therapeutic potential of CXCR4 antagonists in the treatment of HIV. Expert Opin Investig Drugs 2003 Feb;12(2):185-95.

57. Tamamura H, Xu Y, Hattori T, Zhang X, Arakaki R, Kanbara K, et al. A low-molecular-weight inhibitor against the chemokine receptor CXCR4: a strong anti-HIV peptide T140. Biochem Biophys Res Commun 1998 Dec 30;253(3):877-82.

58. Fahham D, Weiss ID, Abraham M, Beider K, Hanna W, Shlomai Z, et al. In vitro and in vivo therapeutic efficacy of CXCR4 antagonist BKT140 against human non-small cell lung cancer. J Thorac Cardiovasc Surg; 2012.

59. Kirshberg S, Izhar U, Amir G, Demma J, Vernea F, Beider $K$, et al Involvement of CCR6/CCL20/IL-17 axis in NSCLC disease progression. PLoS One 2011;6(9):e24856.

60. Eramo A, Lotti F, Sette G, Pilozzi E, Biffoni M, Di Virgilio A, et al. Identification and expansion of the tumorigenic lung cancer stem cell population. Cell Death Differ 2008 Mar;15(3):504-14.

61. Gorelik E, Lokshin A, Levina V. Lung cancer stem cells as a target for therapy. Anticancer Agents Med Chem 2010 Feb;10(2):164-71.

62. Rasheed ZA, Kowalski J, Smith BD, Matsui W. Concise review: Emerging concepts in clinical targeting of cancer stem cells. Stem Cells 2011 Jun;29(6):883-7.

63. Rivera C, Rivera S, Loriot $Y$, Vozenin MC, Deutsch E. Lung cancer stem cell: new insights on experimental models and preclinical data. J Oncol 2011;2011:549181.

64. Ooi AT, Mah V, Nickerson DW, Gilbert JL, Ha VL, Hegab AE, et al. Presence of a putative tumor-initiating progenitor cell population predicts poor prognosis in smokers with non-small cell lung cancer. Cancer Res 2010 Aug 15;70(16):6639-48.

65. Jung MJ, Rho JK, Kim YM, Jung JE, Jin YB, Ko YG, et al. Upregulation of CXCR4 is functionally crucial for maintenance of stemness in drug-resistant non-small cell lung cancer cells. Oncogene 2012.

66. Levina V, Marrangoni A, Wang T, Parikh S, Su Y, Herberman R, et al. Elimination of human lung cancer stem cells through targeting of the stem cell factor-c-kit autocrine signaling loop. Cancer Res 2010 Jan 1;70(1):338-46.

67. Bertolini G, Roz L, Perego P, Tortoreto M, Fontanella E, Gatti L, et al. Highly tumorigenic lung cancer CD133+ cells display stem-like features and are spared by cisplatin treatment. Proc Natl Acad Sci U S A 2009 Sep 22;106(38):16281-6.

68. Damelin M, Geles KG, Follettie MT, Yuan P, Baxter M, Golas J, et al. Delineation of a cellular hierarchy in lung cancer reveals an oncofetal antigen expressed on tumor-initiating cells. Cancer Res 2011 Jun 15;71(12):4236-46

69. Chang A. Chemotherapy, chemoresistance and the changing treatment landscape for NSCLC. Lung Cancer 2011.

70. Peled A, Wald O, Burger J. Development of novel CXCR4-based therapeutics. Expert Opin Investig Drugs 2012 Mar;21(3):341-53.
71. Balkwill FR. The chemokine system and cancer. J Pathol 2012 Jan;226(2):148-57.

72. Burger JA, Kipps TJ. CXCR4: a key receptor in the crosstalk between tumor cells and their microenvironment. Blood 2006 Mar 1;107(5):1761-7.

73. Burger JA, Peled A. CXCR4 antagonists: targeting the microenvironment in leukemia and other cancers. Leukemia 2009 Jan;23(1):43-52.

74. Otsuka S, Bebb G. The CXCR4/SDF-1 chemokine receptor axis: a new target therapeutic for non-small cell lung cancer. J Thorac Oncol 2008 Dec;3(12):1379-83.

75. De Clercq E. The AMD3100 story: the path to the discovery of a stem cell mobilizer (Mozobil). Biochem Pharmacol 2009 Jun 1;77(11):1655-64.

76. DiPersio JF, Stadtmauer EA, Nademanee A, Micallef IN, Stiff PJ, Kaufman JL, et al. Plerixafor and G-CSF versus placebo and G-CSF to mobilize hematopoietic stem cells for autologous stem cell transplantation in patients with multiple myeloma. Blood 2009 Jun 4;113(23):5720-6.

77. DiPersio JF, Uy GL, Yasothan U, Kirkpatrick P. Plerixafor. Nat Rev Drug Discov 2009 Feb;8(2):105-6.

78. Beider K, Abraham M, Peled A. Chemokines and chemokine receptors in stem cell circulation. Front Biosci 2008;13:6820-33.

79. Lapidot T, Dar A, Kollet O. How do stem cells find their way home? Blood 2005 Sep 15;106(6):1901-10.

80. Peled A, Petit I, Kollet O, Magid M, Ponomaryov T, Byk T, et al. Dependence of human stem cell engraftment and repopulation of NOD/SCID mice on CXCR4. Science 1999 Feb 5;283(5403):845-8.

81. Liang Z, Zhan W, Zhu A, Yoon Y, Lin S, Sasaki M, et al. Development of a unique small molecule modulator of CXCR4. PLoS One 2012;7(4):e34038 